\title{
Augmented fluoroscopy and cone beam CT-guided needle biopsy using a steerable guiding sheath: a promising approach for peripheral pulmonary lesions
}

\author{
Masahide Oki ${ }^{1 \wedge}$, Hideo Saka ${ }^{1,2}$ \\ ${ }^{1}$ Department of Respiratory Medicine, National Hospital Organization Nagoya Medical Center, Nagoya, Japan; ${ }^{2}$ Department of Respiratory \\ Medicine, Matsunami General Hospital, Gifu, Japan \\ Correspondence to: Masahide Oki, MD. Department of Respiratory Medicine, Nagoya Medical Center, 4-1-1 Sannomaru, Naka-ku, Nagoya 460-0001, \\ Japan. Email: masahideo@aol.com. \\ Comment on: de Ruiter QMB, Fontana JR, Pritchard WF, et al. Endovascular steerable and endobronchial precurved guiding sheaths for \\ transbronchial needle delivery under augmented fluoroscopy and cone beam CT image guidance. Transl Lung Cancer Res 2021;10:3627-44.
}

Submitted Aug 30, 2021. Accepted for publication Sep 13, 2021.

doi: 10.21037/tlcr-21-696

View this article at: https://dx.doi.org/10.21037/tlcr-21-696

Opportunities to examine patients with small peripheral pulmonary lesions have increased with the evolution of radiological technologies and the increasing availability of computed tomography (CT) screening for lung cancer. An accurate diagnosis is indispensable for decisions regarding optimal management. For patients who require pathological diagnosis to determine appropriate management, nonsurgical biopsy is often performed (1). For non-surgical biopsy procedures, clinicians can use either of two major approaches: image-guided transthoracic biopsies (e.g., CT-guided biopsy and ultrasound-guided biopsy) and transbronchial biopsies (e.g., guided bronchoscopy and robotic bronchoscopy). Image-guided transthoracic biopsy provides a higher diagnostic yield than does transbronchial biopsy; however, it is associated with greater frequencies of complications, such as pneumothorax and hemorrhage $(1,2)$. Bronchoscopy has been widely used as a less invasive procedure for the diagnosis of peripheral pulmonary lesions, although the diagnostic sensitivity of conventional bronchoscopy (using a standard-size bronchoscope under fluoroscopic guidance) for peripheral lung cancer smaller than $20 \mathrm{~mm}$ is reportedly only $34 \%$ (1). Because of this low diagnostic sensitivity, previous lung cancer management guidelines did not recommend using bronchoscopy for the diagnosis of peripheral lung cancer (3). However, over the past two decades, the accuracy of bronchoscopy has dramatically increased with instrumental and technical improvements (2). In more recent lung cancer management guidelines (1), guided bronchoscopy methods [e.g., radial probe endobronchial ultrasound (rEBUS) guidance and navigation device guidance] are suggested for the diagnosis of peripheral pulmonary lesions.

Recent bronchoscopy modifications have facilitated greater diagnostic accuracy by overcoming several limitations of conventional bronchoscopy. The first improvement was confirmation that the biopsy instrument had reached the lesion. Traditionally, biopsy instrument contact with the target lesion during conventional bronchoscopy was confirmed by fluoroscopy alone; however, the spatial relationship between the biopsy instrument and the target lesion cannot be accurately determined by two-dimensional fluoroscopy images. In addition, some lesions (e.g., ground glass nodules and lesions hidden by mediastinal structures) cannot be identified by fluoroscopy (4), and the diagnosis for fluoroscopically invisible lesions is reportedly challenging (5). The development of rEBUS has overcome this limitation; thus, it has dramatically enhanced the diagnostic yield of bronchoscopy $(1,2,4,6,7)$. rEBUS has enabled localization of the target lesion, as well as prediction of biopsy success

^ ORCID: 0000-0003-2164-238X. 
on the basis of the spatial relationship between the lesion and the rEBUS probe (6). Furthermore, rEBUS-guided bronchoscopy is useful for the diagnosis of ground glass nodules (8). Cone beam CT (CBCT) is another technique that can confirm the positions of the biopsy instrument and the target lesion $(9,10)$. It can be used together with rEBUS or as an alternative to rEBUS during bronchoscopy; the diagnostic value of CBCT for peripheral pulmonary lesions has also been reported $(9,10)$. The second improvement was confirmation of the bronchial route leading to the target lesion. Two main navigation systems-electromagnetic navigation bronchoscopy (ENB) and virtual bronchoscopic navigation-are currently available for clinical practice, and the value of navigational bronchoscopy for diagnosing small peripheral pulmonary lesions is well-established (11-14). Augmented fluoroscopy (AF) is a new navigation technology that demonstrates the correct bronchial route to the target lesion on fluoroscopy images in realtime $(15,16)$. Furthermore, CBCT is useful during navigation: it provides real-time feedback regarding the bronchoscope position and the instrument position. The third improvement comprised bronchoscope accessibility and catheter guidance to the peripheral pulmonary lesions. Although the correct bronchial pathway is indicated by the navigation system, bronchoscopy may be unsuccessful when the bronchoscope or biopsy instrument cannot be advanced through the intended pathway. The development of reduced diameter bronchoscopes or catheter alternatives to bronchoscopes (e.g., robotic bronchoscopes and steerable extended working channels), which permit good accessibility through the small bronchus to the peripheral lung, has enhanced the diagnostic yield of bronchoscopy (14,17-21). Recently, a $3.0 \mathrm{~mm}$ ultrathin bronchoscope with a $1.7 \mathrm{~mm}$ working channel was developed; this allows the use of rEBUS and has enabled the implementation of multimodal bronchoscopy (17-19). The fourth improvement was the development of instruments with better sampling ability and better maneuverability. Stiff instruments restrict the flexion range of the bronchoscope and may result in diagnostic failure; thus, increasingly flexible instruments have been developed $(14,22)$. In addition, instruments have been developed to enable the acquisition of larger samples (e.g., cryoprobes) $(22,23)$; these instruments may enhance the diagnostic yield of bronchoscopy. Multimodal bronchoscopy using combinations of some of these improved modalities has improved diagnostic accuracy for small peripheral pulmonary lesions (17).

In a study in the recent issue, de Ruiter et al. evaluated the instrument deliverability of several guiding sheaths (GSs) for performing transbronchial needle aspiration (TBNA) without bronchoscopy under AF and CBCT image guidance (24). The study was conducted in three phases: a bench model, an ex vivo swine lung model, and an in vivo swine model. It compared the instrument delivery accuracies of four precurved GSs $(45,90,180$, and 180 EWC, Medtronic) that are commonly used during ENB, as well as two steerable endovascular GSs (Destino Twist, Oscor Inc.; Morph AccessPro, BioCardia), through the insertion of ENB instruments (e.g., 21-gauge, 19-gauge, and transbronchial access tool needles) and a marker coil. The study showed that the needle delivery errors of steerable GSs, particularly the error of the Destino Twist GS, were smaller than the needle delivery errors of precurved GSs; thus, the use of steerable endovascular GSs might enhance procedural accuracy. In addition, this study in a swine model demonstrated the feasibility of TBNA and fiducial marker delivery using an endovascular steerable GS for small peripheral lung lesions without bronchoscopy under $\mathrm{AF}$ and $\mathrm{CBCT}$ image guidance. The findings suggest that the procedure might be useful for clinical diagnosis and treatment. Indeed, the authors described a patient in whom TBNA was successfully performed using the indicated procedure.

This preclinical study has provided some useful information for current clinical practice, because the results appear applicable to bronchoscopic procedures. The use of a steerable endovascular GS in place of a precurved GS may help to increase the diagnostic accuracy of TBNA during ENB or CBCT/AF-guided bronchoscopy. In addition, the use of a steerable endovascular GS may contribute to accurate localization of peripheral lung cancer via ENB (25). As the authors note, steerable GSs have smaller outer diameters and larger inner diameters, compared to ultrathin bronchoscopes; thus, the procedure may provide good accessibility to the small peripheral airway and enable the use of larger biopsy instruments. However, this procedure lacks direct visualization, which may compromise bleedingrelated safety.

Modifications of techniques and instruments based on such strong investigations should improve the diagnostic yield for small peripheral lung cancer. We hope the authors plan to conduct a clinical trial regarding the efficacy and 
safety of this promising procedure.

\section{Acknowledgments}

Funding: None.

\section{Footnote}

Provenance and Peer Review: This article was commissioned by the editorial office, Translational Lung Cancer Research. The article did not undergo external peer review.

Conflicts of Interest: All authors have completed the ICMJE uniform disclosure form (available at https://dx.doi. org/10.21037/tlcr-21-696). MO reports that he has received speaker fees from Olympus Corp. as an invited guest speaker at academic medical meetings. HS has no conflicts of interest to declare.

Ethical Statement: The authors are accountable for all aspects of the work in ensuring that questions related to the accuracy or integrity of any part of the work are appropriately investigated and resolved.

Open Access Statement: This is an Open Access article distributed in accordance with the Creative Commons Attribution-NonCommercial-NoDerivs 4.0 International License (CC BY-NC-ND 4.0), which permits the noncommercial replication and distribution of the article with the strict proviso that no changes or edits are made and the original work is properly cited (including links to both the formal publication through the relevant DOI and the license). See: https://creativecommons.org/licenses/by-nc-nd/4.0/.

\section{References}

1. Rivera MP, Mehta AC, Wahidi MM. Establishing the diagnosis of lung cancer: diagnosis and management of lung cancer, 3rd ed: American College of Chest Physicians evidence-based clinical practice guidelines. Chest 2013;143:e142S-65S.

2. Wang Memoli JS, Nietert PJ, Silvestri GA. Metaanalysis of guided bronchoscopy for the evaluation of the pulmonary nodule. Chest 2012;142:385-93.

3. Tan BB, Flaherty KR, Kazerooni EA, et al. The solitary pulmonary nodule. Chest 2003;123:89S-96S.

4. Herth FJ, Eberhardt R, Becker HD, et al. Endobronchial ultrasound-guided transbronchial lung biopsy in fluoroscopically invisible solitary pulmonary nodules: a prospective trial. Chest 2006;129:147-50.

5. Jhun BW, Um SW, Suh GY, et al. Preoperative flexible bronchoscopy in patients with persistent ground-glass nodule. PLoS One 2015;10:e0121250.

6. Kurimoto N, Miyazawa T, Okimasa S, et al. Endobronchial ultrasonography using a guide sheath increases the ability to diagnose peripheral pulmonary lesions endoscopically. Chest 2004;126:959-65.

7. Sainz Zuñiga PV, Vakil E, Molina S, et al. Sensitivity of Radial Endobronchial Ultrasound-Guided Bronchoscopy for Lung Cancer in Patients With Peripheral Pulmonary Lesions: An Updated Metaanalysis. Chest 2020;157:994-1011.

8. Ikezawa Y, Shinagawa N, Sukoh N, et al. Usefulness of Endobronchial Ultrasonography With a Guide Sheath and Virtual Bronchoscopic Navigation for Ground-Glass Opacity Lesions. Ann Thorac Surg 2017;103:470-5.

9. Pritchett MA, Schampaert S, de Groot JAH, et al. ConeBeam CT With Augmented Fluoroscopy Combined With Electromagnetic Navigation Bronchoscopy for Biopsy of Pulmonary Nodules. J Bronchology Interv Pulmonol 2018;25:274-82.

10. Cheng GZ, Liu L, Nobari M, et al. Cone beam navigation bronchoscopy: the next frontier. J Thorac Dis 2020;12:3272-8.

11. Folch EE, Pritchett MA, Nead MA, et al. Electromagnetic Navigation Bronchoscopy for Peripheral Pulmonary Lesions: One-Year Results of the Prospective, Multicenter NAVIGATE Study. J Thorac Oncol 2019;14:445-58.

12. Folch EE, Labarca G, Ospina-Delgado D, et al. Sensitivity and Safety of Electromagnetic Navigation Bronchoscopy for Lung Cancer Diagnosis: Systematic Review and Metaanalysis. Chest 2020;158:1753-69.

13. Jiang S, Xie F, Mao X, et al. The value of navigation bronchoscopy in the diagnosis of peripheral pulmonary lesions: A meta-analysis. Thorac Cancer 2020;11:1191-201.

14. Fielding D, Oki M. Technologies for targeting the peripheral pulmonary nodule including robotics. Respirology 2020;25:914-23.

15. Cicenia J, Bhadra K, Sethi S, et al. Augmented Fluoroscopy: A New and Novel Navigation Platform for Peripheral Bronchoscopy. J Bronchology Interv Pulmonol 2021;28:116-23.

16. Pritchett MA. Prospective Analysis of a Novel Endobronchial Augmented Fluoroscopic Navigation System for Diagnosis of Peripheral Pulmonary Lesions. J Bronchology Interv Pulmonol 2021;28:107-15. 
17. Oki M, Saka H, Ando M, et al. Ultrathin Bronchoscopy with Multimodal Devices for Peripheral Pulmonary Lesions. A Randomized Trial. Am J Respir Crit Care Med 2015;192:468-76.

18. Oki M, Saka H, Asano F, et al. Use of an Ultrathin vs Thin Bronchoscope for Peripheral Pulmonary Lesions: A Randomized Trial. Chest 2019;156:954-64.

19. Oki M, Saka H. Diagnostic value of ultrathin bronchoscopy in peripheral pulmonary lesions: a narrative review. J Thorac Dis 2020;12:7675-82.

20. Chen AC, Pastis NJ Jr, Mahajan AK, et al. Robotic Bronchoscopy for Peripheral Pulmonary Lesions: A Multicenter Pilot and Feasibility Study (BENEFIT). Chest 2021;159:845-52.

21. Agrawal A, Hogarth DK, Murgu S. Robotic bronchoscopy for pulmonary lesions: a review of existing technologies and clinical data. J Thorac Dis 2020;12:3279-86.

22. Jiang S, Liu X, Chen J, et al. A pilot study of the ultrathin

Cite this article as: Oki M, Saka H. Augmented fluoroscopy and cone beam CT-guided needle biopsy using a steerable guiding sheath: a promising approach for peripheral pulmonary lesions. Transl Lung Cancer Res 2021;10(9):37013704. doi: $10.21037 /$ tlcr-21-696 cryoprobe in the diagnosis of peripheral pulmonary ground-glass opacity lesions. Transl Lung Cancer Res 2020;9:1963-73.

23. Matsumoto Y, Nakai T, Tanaka M, et al. Diagnostic Outcomes and Safety of Cryobiopsy Added to Conventional Sampling Methods: An Observational Study. Chest 2021. [Epub ahead of print]. 10.1016/ j.chest.2021.05.015.

24. de Ruiter QMB, Fontana JR, Pritchard WF, et al. Endovascular steerable and endobronchial precurved guiding sheaths for transbronchial needle delivery under augmented fluoroscopy and cone beam CT image guidance. Transl Lung Cancer Res 2021;10:3627-44.

25. Bowling MR, Folch EE, Khandhar SJ, et al. Fiducial marker placement with electromagnetic navigation bronchoscopy: a subgroup analysis of the prospective, multicenter NAVIGATE study. Ther Adv Respir Dis 2019;13:1753466619841234. 